\title{
Financing Public Goods by Means of Lotteries
}

JOHN MORGAN

Princeton University

First version received July 1997; final version accepted October 1999 (Eds.)

\begin{abstract}
When viewed as taxes, lotteries are routinely criticized as being both inequitable and inefficient. But is this an entirely fair comparison? Frequently lotteries are used in lieu of voluntary contributions by private charities and governments when taxes are not feasible. When heterogeneous individuals with quasi-linear preferences participate in lotteries whose proceeds will be used to fund a public good, we find that, relative to voluntary contributions, wagers in the unique lottery equilibrium (a) increase the provision of the public good, (b) are welfare improving, and (c) provide levels of the public good close to first-best as the lottery prize increases.
\end{abstract}

\section{INTRODUCTION}

For more than 500 years, governments, private charities, and civic groups have turned to lotteries as a means of financing public goods. This, despite the fact that, over the same span, alternatives to the use of lotteries became cheaper, more sophisticated, and more efficient. Governments devised significantly more effective methods of tax collection and deficit financing, while private charities benefitted from advances in marketing and communications, which opened many new channels for fund-raising. Today global lottery revenues amount to $\$ 75$ billion annually. By any standard, lotteries are a huge industry and show no signs of being completely usurped in favour of other methods of financing public goods. In current economic research, however, there remains extensive debate about both the equity (see Clotfelter and Cook (1987) and Karcher (1989)) and efficiency (see Borg and Mason (1991) and Gulley and Scott (1993)) of lotteries as fund-raising instruments. Much of the analysis of these questions examines lotteries relative to other tax instruments. By this criteria, researchers have largely concluded that, viewed as tax instruments, lotteries do not appear to be a particularly equitable or effective means of revenue generation.

But is this an entirely fair comparison? Lotteries are often held by private charities lacking tax power. Currently in Britain, private charities raise about $8 \%$ (or $£ 500$ million) of their income through lotteries. ${ }^{1}$ In the U.S. in 1992, among 26 reporting states, about $\$ 6$ billion was raised by private charities through lotteries. ${ }^{2}$ Among state governments, legal restrictions such as Proposition 13 in California and the Headlee Amendment in Michigan as well as popular resistance to tax increases of any sort place both de jure as well as de facto limitations on the taxation schemes available to states wishing to increase revenues. Thus, lotteries may not be a substitute for confiscatory tax schemes when these

1. Douglas (1995), Table IV, p. 87.

2. Douglas (1995), p. 357. Since only 26 states report revenues from charitable gambling, the $\$ 6$ billion represents a substantial underestimate of the size of the phenomenon. 
are politically feasible; rather, lotteries are often used in lieu of other voluntary contribution schemes.

Viewed in this light, a much different set of questions about the performance of lotteries is suggested: Are lotteries more effective at financing public goods than other voluntary schemes? If so, how much more effective are they? Can lotteries be used to finance undesirable public goods? Is it "irrational" to participate in a lottery? These questions form the central focus of the paper.

A model of equilibrium wagering behaviour in lotteries whose proceeds (net of prize amounts) are being used to finance a public good is considered. The agents choosing to participate (or not) in the lottery are assumed to have quasi-linear preferences. In such an environment, lotteries are shown to be an effective means of financing public goods relative to other commonly used voluntary mechanisms in a variety of ways. Precisely how lotteries are effective will be made clear below.

\section{Overcoming the free-rider problem}

In this paper, lotteries are viewed as a practical means of trying to overcome the freerider problem in the decentralized allocation of public goods. It is well known that simply asking each agent in an economy to contribute to the public good generally results in the underprovision of the public good relative to first-best levels (see Bergstrom, Blume and Varian (1986) and Andreoni (1988), for example). A variety of solutions to this problem have been offered. The mechanisms suggested by Groves and Ledyard (1977) and Walker (1981) Nash implement first-best public goods allocations. More generally, first-best implementation is possible under a variety of equilibrium and informational assumptions (see Moore (1992) for a survey of more recent advances). Thus, purely as a theoretical exercise, the decentralized public goods provision problem has largely been solved. The evidence for these mechanisms in laboratory settings is somewhat mixed. Chen and Tang (1998) examine the mechanisms of Groves and Ledyard and Walker. In the Groves and Ledyard scheme, a sufficiently high punishment parameter is required to obtain results approaching equilibrium predictions, and the overall conclusion of the paper is that behaviour is better described by various learning models than by equilibrium predictions. Harstad (1982) also examines an iterative version of the Groves and Ledyard mechanism and finds that Nash predictions do poorly. Lotteries differ from the above schemes in that no tax or transfer power is required on the part of the organization conducting the lottery. For organizations with limited ability to impose taxes such as charities, civic groups, or in public broadcasting, this restriction may be important.

Of course, voluntary mechanisms with "provision points" (see Bagnoli and Lipman (1989) and Admati and Perry (1991)) can also lead to first-best outcomes without coercive power on the part of the organization operating them; however laboratory results for these mechanisms also show considerable divergence from equilibrium predictions (see Ledyard (1995), for a survey). Moreover, these mechanisms have two limitations in practice: first, information about preferences is needed to set the provision point appropriately to reach a first-best outcome. Indeed, what happens absent commitment is largely Admati and Perry's point. Second, these mechanisms require commitment power on the part of the organizing agency (or on the part of contributors) to refund (or burn) all contributions in the event that the threshold contribution level is not reached. Lotteries do not have these limitations. Regardless, such mechanisms appear to be seldom employed in practice. 
In contrast, lotteries continue to be a popular and widespread decentralized mechanism for financing public goods. Thus, a model highlighting the strengths and weaknesses of the lottery "mechanism" would seem to be of inherent interest despite the fact that the free-rider problem has, arguably, been solved. In the analysis below, the equilibrium properties of lotteries are contrasted with other commonly used voluntary schemes when efficient public goods allocation can be separated from distributional issues. It is shown that relative to the standard voluntary contributions mechanism, lotteries (a) increase the provision of the public good; (b) are welfare improving; and (c) provide levels of the public good close to first-best as the size of the lottery prize increases.

In comparing lotteries to voluntary contributions, this analysis is in the spirit of Cornes and Sandler (1984) and (1994). In these papers, Cornes and Sandler show that the introduction of a joint public-private good (or impure public good) with a linear price can increase public goods provision relative to the pure public goods case. Further, the impure public goods model has the property that outside donations to the public good are non-neutral. Wagers on lotteries lead to both a chance to win a private prize as well as a contribution to a public good; thus lotteries are a type of joint public-private good; however, the prize structure of the lottery significantly affects its efficacy at alleviating the free-rider problem. When the prize is a fixed amount, lotteries increase the provision of the public good and neutrality does not hold, but when the prize is a constant fraction of total wagers, lotteries do not increase public goods provision and neutrality does hold. As is shown below, differences in prize structure are closely related to differences in the pricing of the joint good.

There are both positive and normative aspects to the results of the paper. On a positive level, the paper provides a formal model which explains the fund-raising capabilities of lotteries in a society consisting of risk-neutral, non-altruistic expected utility maximizers - an environment where one might not expect lotteries to flourish. On a normative level, the finding that certain types of lotteries act to alleviate, though not eliminate, the free rider problem in funding public goods voluntarily suggests their usefulness in fundraising.

Some care is required in these interpretations. The separability assumption of allocation and distribution decisions in the formal model is restrictive but consistent with the goal of the paper: to highlight how the link between lotteries and public goods in giving behaviour affects allocative efficiency in providing a public good. Our intention is not to rule out other explanations of lottery play (such as risk-preference based arguments) or voluntary giving (such as other-regarding preferences), but rather to focus on aspects of the lottery mechanism unique to public goods provision roles of charitable and staterun lotteries. Specifically, we show that non-linear pricing aspects to lotteries introduce a favourable compensating externality serving to ameliorate the free-rider problem.

\section{Linking lotteries and public goods}

Since the link between the lottery and the provision of some public good is crucial to the results highlighted in the paper, it is useful to highlight the connection between lotteries and public goods. Currently, state-run lotteries are operated in 36 U.S. states and the District of Columbia. In fiscal year 1995, revenues from these amounted to just under $\$ 32$ billion, about $\$ 17$ billion of which represented proceeds of the lottery in excess of prizes and administrative costs. ${ }^{3}$ Of this amount, more than half was used to fund education, 
while much of the remainder was used to fund other public goods such as urban renewal, infrastructure development, and environmental preservation. ${ }^{4}$ In short, state-sponsored lotteries are still (mostly) being used to fund public goods.

But does the link between lotteries and public goods affect ticket sales? While no definitive study exists, evidence from several sources seems to suggest that it might. First, indirect evidence of the importance of the linkage may be seen through differences in the payout rates of casino-run bingo and keno games (about $80 \%$ ), where the link to public goods is absent, and the payout rates of state and charitably run gambling (about 50\%), where the link is present. The same difference in payouts may be observed in comparing illegal to state-run numbers games. Indeed, the perceived importance of linking the proceeds of a lottery with funding some public good is also suggested by the fact that 21 of 36 lottery states explicitly earmark the proceeds of lotteries to support certain types of public goods. ${ }^{5}$ For instance, eleven states specifically require that $100 \%$ of lottery proceeds be used to fund education. However, there is considerable debate over the effectiveness of earmarking as a budgeting device due to the fungibility of state revenues (see Buchanan (1963), Borg and Mason (1988), and Goetz (1968)). Regardless, the psychological importance of the linkage, perhaps through "flypaper effects" (Hines and Thaler (1995)) may be observed by comparing wagering behaviour in earmarking versus non-earmarking states.

As Figure 1 shows, states which earmark have higher average per capita lottery expenditures than states which do not earmark; thus suggesting that consumers pay some attention to the public goods benefits in deciding how much to bet. In a laboratory setting,

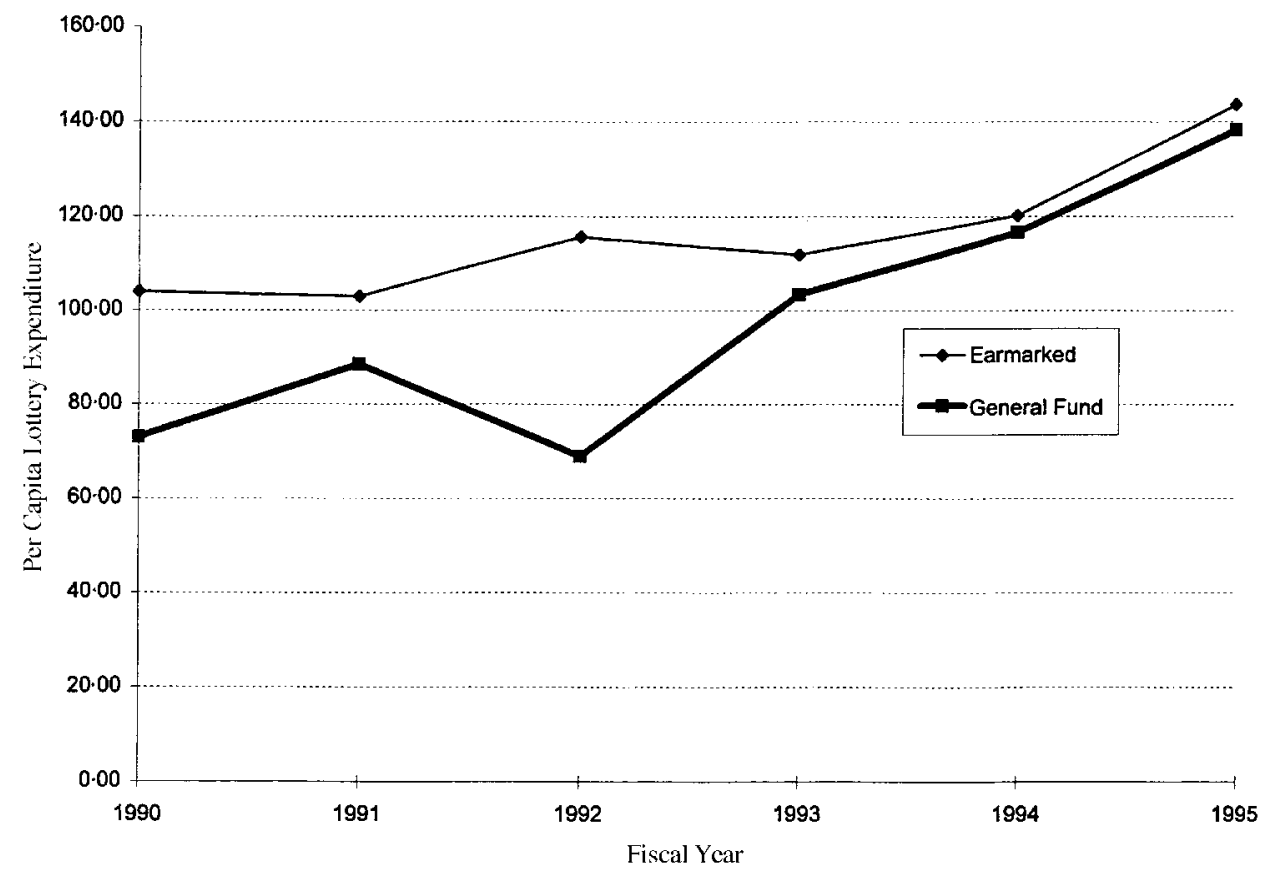

Figure 1

Earmarking vs. general fund

(Sources: Statistical Abstract of the United States, 1991-1995; La Fleur's Lottery World)

4. U.S. Department of Commerce (1995).

5. La Fleur and La Fleur, Lottery FAQ. 
Morgan and Sefton (2000) show that changes in the desirability of the public good significantly affect betting behaviour.

Advertising expenditures by states also suggest the linkage is important. Approximately $4 \%$ of television lottery advertising content consists of information concerning the public benefit from lotteries. ${ }^{6}$ In some lottery states, such as Pennsylvania, where the lottery proceeds are particularly narrowly targeted, this percentage is much higher. While $4 \%$ is by no means a large percentage of advertising time to devote to the link to public goods, it is far more than one would expect if bettors paid no attention whatsoever to the purpose for which the lottery proceeds were being used. Additional anecdotal evidence illustrating the importance of this linkage may be seen in the comments of a Pennsylvania revenue official, who notes that, "One of the secrets of the Pennsylvania lottery is having targeted the proceeds. And having the public know where the money goes really seems to help ticket sales." 7 To sum up, lotteries are frequently linked to the provision of public goods, and this linkage does seem to affect betting behaviour.

The paper proceeds as follows. Section 2 outlines the basic model and analyses two benchmark cases: the socially optimal provision of the public good and the provision via voluntary contributions. In Section 3, equilibrium wagering behaviour with the introduction of a fixed-prize raffle is characterized. Relative to voluntary contributions, the introduction of a raffle increases the provision of the public good. Section 4 examines equilibrium behaviour in a pari-mutuel raffle where prize amounts are determined endogenously. In Section 5, it is shown that the lottery results may be reinterpreted as applying to the class of gambling games referred to as lottos, impure public goods models, and as non-linear subsidies. Section 6 shows that the main results hold whenever the public goods allocation decisions can be separated from distribution decisions. Finally, Section 7 concludes. Proofs to the main theorems and propositions are contained in the Appendix.

\section{PRELIMINARIES}

Suppose that an economy consists of a set $N=\{1,2, \ldots, n\}$ of consumers (also referred to as bettors when appropriate) with quasi-linear utility functions of the form

$$
U_{i}=w_{i}+h_{i}(G) \text {. }
$$

$\mathrm{w}_{i}$ is a numeraire good which denotes the wealth of consumer $i$, and $G \in \mathfrak{R}_{+}$denotes the level of the public good provided. Consumers experience diminishing marginal utility from the provision of the public good; hence, $h_{i}^{\prime}(\cdot)>0$ and $h_{i}^{\prime \prime}(\cdot)<0$ for all $i$. The public good is generated by transforming the numeraire good into $G$, on a one-for-one basis, and consumers are assumed to maximize their expected utility. In Section 6, we show that the results of the paper hold whenever public goods allocation decisions can be separated from distribution decisions.

\section{Social optimum}

Consider the social optimization problem which seeks to maximize aggregate surplus in the economy. The social optimization problem is to choose the total wealth ${ }^{8}$ in the

6. Douglas (1995), p. 355.

7. Douglas (1995), p. 365.

8. Notice that with the given utility specification, the particular consumers required to contribute wealth to the public good are irrelevant. 
economy to be transformed into the public good. Formally, a social planner chooses $G \leqq \sum_{i=1}^{n} w_{i}$ to maximize

$$
W=\sum_{i=1}^{n}\left(w_{i}+h_{i}(G)\right)-G .
$$

At an interior solution, ${ }^{9}$ the optimal amount of the public good, $G^{*}>0$ solves

$$
\sum_{i=1}^{n} h_{i}^{\prime}\left(G^{*}\right)=1,
$$

which is the well-known Samuelson Criterion for welfare maximization. When $G^{*}>0$, the public good is said to be socially desirable. However, if

$$
\sum_{i=1}^{n} h_{i}^{\prime}(0)<1,
$$

then it is not optimal to provide positive amounts of the public good, i.e. $G^{*}=0$, and the public good is said to be socially undesirable. Social desirability proves to be a useful criterion in assessing the public goods provision abilities of raffles and lottos as compared to voluntary contributions.

\section{Voluntary contributions}

Now suppose that the government or charitable organization chooses to rely on voluntary contributions for the provision of the public good. There are numerous instances of such voluntary contribution schemes being employed in practice such as Public Broadcasting System (PBS) fund drives, university telemarketing campaigns, direct mail requests for funds from environmental and civic groups, and street corner solicitations by little leaguers; moreover, many of these groups also rely on lotteries for fund-raising. Thus, it seems useful to compare voluntary contributions to lotteries.

Let $x_{i}$ denote the amount of wealth contributed by $i$, and let $x(S)$ denote the sum of contributions by a set $S \subseteq N$ of consumers. Thus, $x(N)$ denotes the total contributions of all consumers.

Given the contributions of all other consumers, $i$ chooses $x_{i} \in\left[0, w_{i}\right]$ to maximize

$$
U_{i}=w_{i}-x_{i}+h_{i}(x(N)) \text {. }
$$

A Nash equilibrium to the voluntary contribution game consists of an n-tuple $\left(x_{1}^{V}, x_{2}^{V}, \ldots, x_{n}^{V}\right)$ of contribution amounts. The equilibrium public goods provision is then given by $G^{V}=x^{V}(N)$. In the quasi-linear framework of the model, the following wellknown result characterizes equilibrium contributions (see Bergstrom, Blume and Varian (1986) for details).

Proposition 1. With quasi-linear preferences, voluntary contributions underprovide the public good relative to first-best levels.

Contributors do not internalize the benefit conferred upon all other consumers when deciding how much to contribute to the public good; thus, each consumer tends to undercontribute relative to what would be socially optimal. In the aggregate, this leads to

9. Throughout the paper, wealth constraints are assumed to be non-binding for all consumers. While binding wealth constraints are known to have significant strategic effects in auction settings, consideration of such effects would merely confound the analysis of the economic forces generated by the introduction of a raffle. As a practical matter, wealth constraints do not appear to play a significant role in determining betting behaviour in lotteries. 
a systematic underprovision of the public good. Indeed, when the public good is socially desirable, extreme free-riding is possible. For instance, suppose that for all $i, h_{i}^{\prime}(0)=1 /(n-1)$, then even though the public good is socially desirable, no consumer will contribute to it. Voluntary contributions also suffer a multiplicity of equilibria; specifically, if two or more consumers ( $i$ and $j$, say) contribute positive amounts of the public good, then there are a continuum of equilibria such that $x_{i}^{V}+x_{j}^{V}=G^{V}$.

As was mentioned above, the underprovision problem in this mechanism can be remedied by the introduction of a provision point set equal to $G^{*}$. Notice, however, that this is not identical to the familiar fund-raising strategy of setting a suggested contribution amount or posted funding target. Both suggested contributions and funding targets are, in effect, "cheap talk" on the part of the fund-raiser in the sense that they have no direct effect on the payoffs each consumer faces when deciding on how much to contribute. ${ }^{10} \mathrm{In}$ the event that (say) United Way fails to meet its funding target, consumers do not expect that their contributions will be returned. In contrast, the provision point mechanism does change the payoffs of the consumers.

\section{FIXED-PRIZE RAFFLES}

The raffle is one of the oldest and simplest types of lottery consisting of little more than some numbered tickets and a pre-announced prize. The simplicity and fairly low expense in setting up and administering a raffle no doubt account for the continued popularity of this game. In addition, the well-known games Bingo and Keno, also often used by charities and state lotteries for fund-raising, represent straightforward variations on the raffle idea.

A fixed-prize raffle is modelled as follows: The government or charitable organization chooses a prize, denominated in wealth, of some fixed amount $R$. The value of the prize is the same for all bettors and is commonly known. The $i$-th bettor chooses a wager of $x_{i} \in\left[0, w_{i}\right]$ which, given the wagers of the other contestants, $x_{-i}$, yields a probability of $i$ winning the contest of

$$
\pi\left(x_{i}, x_{-i}\right) \equiv \frac{x_{i}}{x(N)},
$$

where, as before, $x(N)$ denotes the sum of all wagers and $x(N \backslash i)$ denotes the sum of the wagers of all bettors excluding $i .^{11}$

Since the charity must pay for the prize, the public good provision consists of the excess of wagers over $R$; that is

$$
G=x(N)-R .
$$

Suppose that charity has access to an arbitrarily small amount of deficit financing of an amount $\delta$. If the wagers are within $\delta$ of $R$, then the charity proceeds with the raffle as usual. ${ }^{12}$ If the wagers are insufficient to cover the cost of the prize, then the charity calls

10. This is not to say that cheap talk does not matter in this setting. Experimental work by Isaac and Walker (1988) suggests that communications among consumers can increase contribution rates. However, the effect of cheap talk on the part of the public goods provider remains an open question.

11. Weesie (1990) studies a similar competitive structure in a model explaining volunteerism. In his model, individuals compete in voluntary effort to obtain recognition and social status.

12. This assumption eliminates the possibility of a second equilibrium, where, knowing the raffle will be called off anyway, all bettors contribute zero. Notice that in the case of voluntary contributions with provision points, such a device would not eliminate the inefficient equilibria. 
off the raffle and returns each bettor's wager.

$$
E U_{i}=w_{i}-x_{i}+\frac{x_{i}}{x(N)} R+h_{i}(x(N)-R),
$$

provided that the raffle is held. ${ }^{13}$

Differentiating with respect to $x_{i}$ yields the first-order condition

$$
\frac{x(N \backslash i)}{(x(N))^{2}} R-1+h_{i}^{\prime}(x(N)-R) \leqq 0 .
$$

It is useful to observe that when $R=0$; this is identical to the first-order condition for voluntary contributions without a provision point.

The next set of results characterizes the Nash equilibrium of the fixed-prize raffle for the case in which the public good is socially desirable. All proofs are relegated to the Appendix.

Proposition 2. When consumers have quasi-linear preferences, the fixed-prize raffle has a unique equilibrium.

Unlike voluntary contributions, which are plagued with a multiplicity of equilibria, the fixed-prize raffle has a unique equilibrium as a result of the introduction of competition to win the private prize among bettors.

\section{Raffles in lieu of voluntary contributions}

Suppose that a raffle is used to replace an ordinary voluntary contributions campaign, such as a PBS fund drive. The potential contributors to PBS tend to be relatively well educated and are probably sophisticated enough to see through the incentives in a simple raffle. This being the case, should PBS replace its fund drive with a fixed-prize raffle? On the one hand, the introduction of a fixed-prize raffle will introduce the chance to win a private prize which will naturally increase contributions amounts by viewers. Unfortunately for PBS, having to pay for the prize represents an additional cost which will reduce the amount of contributions available to pay for programming. Thus, it seems unclear that the raffle will be an improvement. However:

Theorem 1. When preferences are quasi-linear, the fixed-prize raffle provides more of the public good than the voluntary contributions.

Intuitively, the problem with the voluntary contributions campaign is that the public good exhibits positive externalities which are not accounted for in the contribution decisions of each individual. The introduction of a fixed-prize raffle creates an investment fund with a negative externality component. That is, when a consumer purchases more raffle tickets, he reduces the chances of winning of all other bettors. This negative externality compensates for the positive externality; thus reducing the gap between the private

13. Provided that $x(N \backslash i)-R \geqq 0$, then $E U_{i}$ is globally concave in $x_{i}$; hence the simultaneous satisfaction of first-order conditions is sufficient for an equilibrium. If $x(N \backslash i)-R<0$, then, noting that equilibrium payoffs are positive (whereas we can normalize payoffs to zero if the raffle is called off), simultaneous satisfaction of first-order conditions is still sufficient under these circumstances. 
and social marginal benefit of contributions. As a result, equilibrium contributions increase.

Is there any benefit to combining lotteries and voluntary giving as a means of financing the public good? The answer is no. The additional benefit associated with the possibility of obtaining the prize, while at the same time increasing the provision of the public good with one's contributions implies that the benefit an individual derives from lottery contributions will always exceed that obtained via voluntary giving. That is, conditional on making a donation, donating via the fixed-prize lottery dominates donations via voluntary contributions. This leads to a sharp prediction regarding the effects of lotteries on voluntary giving.

Corollary 1. When preferences are quasi-linear, fixed prize raffles completely crowd out voluntary giving.

But how much do contributions increase with the introduction of a fixed-prize lottery? Below we show that the fixed-prize raffle provides less of the public good than the social optimum and hence is always welfare improving relative to voluntary contributions. To see this, suppose that the fixed-prize raffle provided exactly the socially optimal amount of the public good. If, in this equilibrium, only the first $n^{\prime}$ bettors wagered positive amounts then

$$
\sum_{i=1}^{n^{\prime}} h_{i}^{\prime}\left(G^{*}\right)-n^{\prime}+\left(n^{\prime}-1\right) \frac{R}{R+G^{*}}=0 .
$$

However, we also know that $\sum_{i=1}^{n} h_{i}^{\prime}\left(G^{*}\right)=1$ when the public good is socially optimal. Thus,

$$
\begin{aligned}
\sum_{i=1}^{n^{\prime}} & h_{i}^{\prime}\left(G^{*}\right)-n^{\prime}+\left(n^{\prime}-1\right) \frac{R}{R+G^{*}} \\
& \leqq \sum_{i=1}^{n} h_{i}^{\prime}\left(G^{*}\right)-n^{\prime}+\left(n^{\prime}-1\right) \frac{R}{R+G^{*}} \\
& =\left(n^{\prime}-1\right)\left(\frac{R}{R+G^{*}}-1\right) \\
& <0
\end{aligned}
$$

hence the raffle must provide less of the public good than the first-best levels. It then readily follows that the introduction of a fixed-prize raffle is unambiguously welfare improving over voluntary contributions since it always provides levels of the public good which are closer to first-best.

Although the introduction of the fixed-prize raffle reduces the gap between the private and social marginal benefits of bettors' contribution decisions, the structure of the game is such that the negative externalities are never sufficient to completely cancel the positive externalities from giving to the public good. These compensating externality effects may be easily quantified for the case of $n$ identical bettors who value the public good according to $h(\cdot)$. The social marginal benefit of providing $G$ of the public good is simply $n h^{\prime}(G)$; whereas the private marginal benefit is $h^{\prime}(G)$. Thus, the positive externality associated with contributing the $G$-th dollar to the public good is $(n-1) h^{\prime}(G)$. The introduction of 
a fixed-prize raffle creates a compensating negative externality. Now, by choosing to contribute $x$ when the total wagers by other bettors are $y$, a bettor reduces the expected payoffs of the other bettors by $y /\left((x+y)^{2}\right) R$. In equilibrium, this term simplifies to $((n-1) / n)(R /(R+G))$, and the net externality, $E(R)$, as a function of the prize offered becomes

$$
E(R)=\frac{(n-1)}{n}\left(n h^{\prime}(G)-\frac{R}{R+G}\right) .
$$

Since $R=0$ under voluntary contributions, the introduction of a fixed-prize raffle reduces the gap between the private and social incentives.

\section{First-best raffles}

How does the level of public goods provision in a raffle compare with the social optimum? While a fixed-prize raffle cannot generate the socially optimal provision of the public good, it can come arbitrarily close to the first-best outcome. The intuition behind this is that the need to award a prize to some bettor, creates a "wedge" between the optimal provision of the public good and the amount provided by the raffle. This wedge may be reduced by making the prize amounts sufficiently large to induce bettors to bet closer to first-best levels, but it cannot be completely eliminated.

Theorem 2. Suppose that all individuals have quasi-linear preferences, then given any $\varepsilon>0$, there exists an economy of size $\sum_{i=1}^{n} w_{i}^{*}$ and a raffle with prize $R^{*}$ such that the public goods provision induced by the raffle lies within $\varepsilon$ of the first-best outcome.

If we again return to the identical $n$ bettor case, notice that the gap between the private and social marginal benefit, equation (4), is decreasing as a function of the prize amount of the raffle, $R$. As $R$ becomes arbitrarily large, $R /(R+G) \rightarrow 1$; moreover, as $G \rightarrow G^{*}, n h^{\prime}(G) \rightarrow 1$. Thus, increasing the prize reduces the gap between private and social incentives and generates public goods provisions arbitrarily close to first-best levels.

\section{Neutrality}

In the private provision of public goods, the possibility of "crowding out" of private donations by government contributions is well-known. Bergstrom, Blume and Varian (1986) and Warr (1982) show that government contributions crowd out private donations on a one-for-one basis in a general setting. Andreoni (1988) and Bernheim (1986) demonstrate the neutrality of a wide range of policies when a public good is funded through voluntary contributions without a provision point. Thus, there is no role for tax or redistribution policies in these models. Cornes and Sandler (1984), (1994) show that in models with impure public goods, neutrality does not hold. This is also the case when a good is funded by means of a fixed-prize raffle.

In the case of a fixed-prize raffle, given a small donation $D$, the sum of first-order conditions for positive bettors becomes

$$
\sum_{i=1}^{N^{\prime}} h_{i}^{\prime}(\bar{x}(N)+D-R)-N^{\prime}+\left(N^{\prime}-1\right) \frac{R}{\bar{x}(N)}=0 .
$$


Totally differentiating and rearranging

$$
\frac{\partial \bar{x}(N)}{\partial D}=\frac{-\sum_{i=1}^{N^{\prime}} h_{i}^{\prime \prime}(\bar{x}(N)+D-R)}{\sum_{i=1}^{N^{\prime}} h_{i}^{\prime \prime}(\bar{x}(N)+D-R)-\left(N^{\prime}-1\right) R /(\bar{x}(N))^{2}} \geqq-1,
$$

and since, in absolute value, the denominator of this expression is larger than the numerator, crowding out is less than one-for-one in this circumstance. Thus.

Proposition 3. In a fixed-prize raffle when preferences are quasi-linear, small donations will increase the total provision of the public good.

Incomplete crowding out suggests that an organization might wish to make an outside donation to increase the level of the public good. One common way in which such donations are made is by contributing directly to the prize pool rather than to the public good directly. Is this the most effective manner of contributing? Combining the results of Proposition 3 and Theorem 2 yields.

Corollary 2. In a fixed-prize raffle when preferences are quasi-linear, small donations to the prize pool provide more of the public good than direct contributions.

To see this, observe that a direct contribution, $D$, to the public good results in the following optimization for $i$

$$
\max _{x_{i}} U_{i}=\frac{x_{i}}{x(N)} R-x_{i}+h_{i}(x(N)-R+D) .
$$

In contrast, a contribution to the prize pool results in the optimization

$$
\max _{x_{i}} U_{i}=\frac{x_{i}}{x(N)}(R+D)-x_{i}+h_{i}(x(N)-R),
$$

which may be rewritten as

$$
\max _{x_{i}} U_{i}=\frac{x_{i}}{x(N)}(R+D)-x_{i}+h_{i}(x(N)-R-D+D) .
$$

Letting $R+D=R^{\prime}$, then

$$
\max _{x_{i}} U_{i}=\frac{x_{i}}{x(N)} R^{\prime}-x_{i}+h_{i}\left(x(N)-R^{\prime}+D\right) .
$$

But this is equivalent to donating $D$ directly and increasing the prize offered from $R$ to $R^{\prime}$. Since crowding out is less than one for one and public goods provision is increasing in the size of the prize offered, the result then follows.

\section{Extreme free riding}

As was mentioned earlier, voluntary contributions also suffer from the drawback that socially desirable public goods may go unfunded entirely. While the fixed-prize raffle provides more of the public good than voluntary contributions, it might still be the case that some socially desirable public goods also go entirely unfunded by raffles. However, it turns out that the negative externality effect of introducing the raffle is always sufficient 
to generate bets in excess of the prize for all socially desirable public goods and never sufficient to generate bets in excess of the prize for socially undesirable public goods. More formally.

Theorem 3. When preferences are quasi-linear, the fixed-prize raffle provides positive amounts of the public good if and only if the good is socially desirable.

\section{PARI-MUTUEL RAFFLES}

In this section, the prize amount of the raffle is made endogenous. That is, instead of designating a fixed-prize amount, the government or charitable organization designates a percentage of total wagers to be placed in a prize pool. Specifically, in a pari-mutuel raffle, some percentage, $p$, of the "handle" (the total bets) is rebated in the form of prizes. As with voluntary contributions, assume that there is no cost to administer the raffle; hence $(1-p)$ of the handle is used to fund a public good.

In a pari-mutuel raffle, the utility maximization problem becomes to choose $x_{i}$ (given the wagers of all other bettors, $x_{-i}$ ) to maximize

$$
E U_{i}=w_{i}+\left(\frac{x_{i}}{x(N)}\right) p B-x_{i}+h_{i}((1-p) B),
$$

where $B \equiv x(N)$, the total wagers of all bettors.

Differentiating with respect to $x_{i}$ yields

$$
p-1+h_{i}^{\prime}((1-p) B)(1-p) \leqq 0 .
$$

Thus, $i$ chooses a wager satisfying

$$
h_{i}^{\prime}((1-p) B)-1 \leqq 0,
$$

but this is identical to the optimization conditions under voluntary contributions without a provision point. The following result is immediate; hence no proof is given.

Proposition 4. The equilibrium public goods provision in a pari-mutuel raffle is exactly the same as that obtained through voluntary contributions without a provision point.

Intuitively, the pari-mutuel prize structure "dilutes" the negative externality effects of a fixed-prize raffle. Additional bets continue to reduce the chance of winning for all other bettors, so the negative externality component continues to be present. However, such bets simultaneously increase the prize pool available to all other bettors thus introducing an additional positive externality. In the quasi-linear case, these two externalities exactly offset each other, and only the positive externality effects of contributing to the public good remain. Naturally, this leads to contributions yielding an outcome identical to voluntary contributions without a provision point and neutrality once again holds. For more general utility specifications, the increase in the prize pool will not exactly cancel the reduction in winning chances; however, the dilution of the negative externality will still be present. As a result, a pari-mutuel raffle will continue to be less effective at providing public goods than its fixed-prize counterpart. 


\section{INTERPRETATION OF RESULTS}

In this section, we offer several alternative interpretations of our results on the efficiency properties of raffles. First, the lottery model is compared to the impure public good models of Cornes and Sandler (1984), (1994). Next, we establish an outcome equivalence between raffles and the class of gambling games often referred to as lottos. Finally, we establish outcome equivalence between raffles and non-linear subsidy schemes when individuals have quasi-linear preferences.

Lotteries as impure public goods. The possibility of a compensating externality from the introduction of a joint private-public good was also highlighted in two papers by Cornes and Sandler (1984), (1994). Their framework allows for quite general preference relationships, a special case of which are the preferences assumed in this paper; that is, where the private characteristics of the impure public good are a perfect substitute for the numeraire good, and there is additive separability between private and public goods. In Cornes and Sandler, the price per unit of the joint good is fixed. An implication of their analysis for the preference structure of the lottery model is that public goods provision will not increase at all with an impure public good. ${ }^{14}$ Interestingly, a pari-mutuel lottery is strategically equivalent to a joint good with a fixed price per unit in this setting. In a fixed prize lottery, however, the price per unit of the joint good varies depending on total wagers, and, as shown above, this significantly affects the publc goods provision of the lottery.

Lotto. Lotto is the most popular and fastest growing of the lottery games offered in the U.S. Lotto ticket sales account for more than half of all lottery ticket revenues in the U.S. and almost three quarters of lottery revenues globally. Typically, the prize structure in lotto is hybrid, having both fixed prize and a pari-mutuel components. The fixedprize components of lotto games come from two sources, guaranteed minimum payouts regardless of ticket sales and prize money rolled over from previous drawings in which there was no winner. Once ticket sales for a lotto drawing exceed some threshold, the prize pool is augmented in pari-mutuel fashion with a fixed percent of the handle being added to the prize pool.

To most easily see the structure of the lotto game, it is helpful to begin by considering a pure fixed-prize version of the game. In a fixed-prize lotto, a government or charitable organization offers $K$ possible winning numbers (or combinations of numbers) and a fixed prize $R>0$.

Bettors who bet on a number $k$ which wins the lotto, then share the prize in proportion to their bets as a percentage of the total amount bet on $k$. With $n$ bettors, the utility maximization problem of better $i$, given the wagers of the other bettors is to choose a $K$ vector of bets $x_{i}=\left(x_{i 1}, x_{i 2}, \ldots, x_{i K}\right)$ corresponding to each of the $K$ numbers which maximize

$$
E U_{i}=w_{i}+\sum_{k=1}^{K}\left(\frac{1}{K}\left(\frac{x_{i k}}{x_{i k}+y_{k}}\right) R-x_{i k}\right)+h_{i}\left(\sum_{k=1}^{K}\left(x_{i k}+y_{k}\right)-R\right),
$$

14. To see this, let the price per unit of the joint good be given by $p$. Suppose that the joint good provides $\beta$ units of the private characteristic and $\gamma$ units of the public characteristic. Then the utility of an individual buying $x_{i}$ units of the joint good given the purchases of all other individuals may be written as

$$
U_{i}=w_{i}-z_{i}+h_{i}\left(\sum_{j=1}^{n} \frac{\gamma}{p-\beta} z_{j}\right)
$$

where $z_{i}=(p-\beta) x_{i}$. It is clear that this is equivalent to a voluntary contribution mechanism where the numeraire is transformed into the public good at the rate $\gamma /(p-\beta)$. 
where $y_{k}=\sum_{j \neq i} x_{j k}$ denotes the sum of the wagers of the other bettors on the $k$ th number in the lotto.

Notice that, conditional on the winning number $k$, the payoff structure for the lotto is identical to that of the raffle. Thus, if all of the bettors knew what the winning number would be, their bets would be identical to those of the raffle. In reality, bettors are symmetrically uninformed about which number will be the winning one. Since all numbers have an equal probability of being winners, bettors simply divide their bets (knowing the winning number) evenly among all the numbers. Thus, their betting behaviour in the lotto game is identical to the raffle, and the two games are outcome equivalent in the sense that total equilibrium wagers by each bettor are identical to a similarly structured raffle. ${ }^{15}$ It is a simple matter to show that outcome equivalence between lottos and raffles extends to equilibrium betting on pari-mutuel forms of each game. As a result, all of the results derived for raffles also hold for lottos.

Gulley and Scott (1993) observe that an empirical regularity of lotto play is that the occurrence of rollovers generates much increased betting on lotto, often in excess of the amount of the increase in the prize amount. DeBoer (1990), and Gulley and Scott (1993) used this variation in the prize pool to recommend changes in the odds structure to induce additional rollovers and generate greater lotto revenue. Notice, however, that the changes in betting behaviour associated with rollovers correspond to changing the level of the fixed prize component of the lotto. As was shown earlier, increasing the fixed prize leads to increased provision of the public good net of prize amounts; that is, bets increase in excess of the amount of the prize. Thus, the observed behaviour is consistent with the predictions of the model. In light of this, the data might be interpreted in support of a much different policy prescription. That is, reducing the parti-mutuel component of the prize structure while increasing the fixed prize component (with no change in the odds) should also yield higher lotto revenues.

Lotteries as subsidy schemes. The extant literature on subsidies examines schemes where the amount of the subsidy rebated to individual $i$ is linear in $i$ 's contribution to the public good. Moreover, these subsidies (as well as the public good itself) are financed through the imposition of confiscatory taxes. ${ }^{16}$ Typically, these taxes are chosen such that, when individuals make privately optimal decisions, tax receipts are just sufficient to cover subsidy outlays. Thus, individuals are assumed not to have the right to "opt out" of the mechanism and the planner is assumed to know all of the preferences of the individuals in order to choose budget-balancing taxes. Below we establish an equivalence between lotteries and certain types of subsidy schemes which differ from the existing literature along three dimensions. First, when viewed as subsidies, lotteries are shown to be budget balancing even when the planner is completely ignorant of the preferences of the individuals in the economy. Second, fixed-prize lotteries are seen to be subsidies that are nonlinear in the amount rebated for contributions to the public good. Finally, lotteries are subsidies that require no confiscatory tax power on the part of the public goods provider. Put another way, lotteries may be viewed as subsidies where individuals do have the right to opt out of the mechanism if they so desire. We begin with fixed prize lotteries.

15. Some care is needed here. Outcome equivalence follows from risk neutrality. In general, raffles and lottos will not be outcome equivalent; however, the compensating externality effects which yield increased provision of the public good with the introduction of a fixed-prize raffle will still be present with the introduction of a fixed-prize lotto. (1987).

16. See, for instance, Andreoni (1988), Andreoni and Bergstrom (1996), Bernheim (1986), and Roberts 
Remark 1. With quasi-linear preferences, a fixed-prize lottery is outcome equivalent to a subsidy scheme of the following form: The organization financing the public good stipulates a rebate amount $R$ which will be set aside from total contributions (provided that these exceed $R$ ). Each individual receives a rebate share that is proportional to his or her contributions to the public good relative to total contributions.

In this case, the subsidy rate of every individual is given by

$$
s(x(N) ; R)=\frac{R}{x(N)} .
$$

Thus, the individual subsidy rate is determined in equilibrium by the level of contributions to the public good. The total cost of the subsidies is simply

$$
\sum_{i=1}^{n} s(x(N) ; R) x_{i}=s(x(N) ; R) \sum_{i=1}^{n} x_{i}=\frac{R}{x(N)} \times x(N)=R .
$$

Hence the scheme is budget balancing. With such a scheme in place, the optimization problem faced by individual $i$ given contributions $x(N \backslash i)$ is simply to choose $x_{i}$ to maximize

$$
U_{i}=w_{i}-\left(1-s\left(x(N \backslash i)+x_{i} ; R\right)\right) x_{i}+h_{i}\left(x_{i}+x(N \backslash i)-R\right),
$$

and it is immediate that this is equivalent to a fixed-prize lottery.

However, the asymptotic efficiency result presented in Theorem 2 does not hold for any non-linear subsidy scheme. To see this, consider the following parametric class of nonlinear subsidies for the simple case where all $N$ individuals in an economy are identical. Let the subsidy scheme of the form

$$
s_{i}\left(x_{i}, x(N) ; R\right)=\frac{x_{i}^{\alpha}}{\sum_{j=1}^{N}\left(x_{j}\right)^{\alpha}} \frac{R}{x_{i}} .
$$

Notice that the fixed-prize lottery scheme is a special case where $\alpha=1$. Computing a pure strategy symmetric equilibrium ${ }^{17}$ consisting of non-negative contributions to the public good leads to the equilibrium public goods provision $G_{\alpha}$ solving

$$
N h^{\prime}\left(G_{\alpha}\right)=N-\frac{N-1}{N} \frac{\alpha R}{R+G_{\alpha}} .
$$

Taking limits, we have that when $\alpha<1, \lim _{R \rightarrow \infty} G_{\alpha}<G^{*}$, and when $\alpha>1$, $\lim _{R \rightarrow \infty} G_{\alpha}>G^{*}$. Thus, the fixed-prize raffle is the unique non-linear subsidy in this class that approaches first-best public goods provision as $R$ grows large. For finite $R$, however, it is easy to establish that $G_{\alpha}$ is increasing in $\alpha$. That is, increasing the degree of convexity of the non-linear scheme increases the amount of the negative externality and hence increases public goods provision.

In contrast, the pari-mutuel lottery may be readily seen to be equivalent to a linear subsidy scheme.

Remark 2. With quasi-linear preferences, a pari-mutuel lottery is outcome equivalent to a subsidy scheme of the following form: The organization financing the public good stipulates a flat subsidy $s=p$. The total amount of the subsidy will be financed from total contributions.

17. Provided $\alpha$ is not too large, such an equilibrium always exists. 
With such a scheme in place, the optimization problem faced by individual $i$ given contributions $x(N \backslash i)$ is simply to choose $x_{i}$ to maximize

$$
U_{i}=w_{i}-(1-s) x_{i}+h_{i}\left((1-s)\left(x_{i}+x(N \backslash i)\right)\right),
$$

and it is immediate that this is equivalent to a pari-mutuel lottery. This also highlights the fact that, when individuals have the right to opt out of a tax-subsidy scheme, then flat subsidies are neutral.

\section{ROBUSTNESS OF EFFICIENCY GAINS FROM LOTTERIES}

In this section, we show that our results are robust to a specification of preferences where income effects are present, but where the public goods allocation decision is separate from distributional decisions. Bergstrom and Cornes (1983) showed that this separation is essentially equivalent to assuming that individual preferences can be represented as quasi-concave utility functions of the form

$$
U_{i}=w_{i} H(G)+h_{i}(G)
$$

where $H(\cdot)>0$.

For simplicity, we assume interior solutions obtain for all persons in the economy. Recalculating the first-best benchmark, we have

$$
\sum_{i=1}^{n} h_{i}^{\prime}\left(G^{*}\right)=H\left(G^{*}\right)-H^{\prime}\left(G^{*}\right)\left(\sum_{i=1}^{n} w_{i}-G^{*}\right) .
$$

In contrast, voluntary contributions imply public goods level $G^{V}$ which solves the sum of first-order conditions:

$$
\sum_{i=1}^{n} h_{i}^{\prime}\left(G^{V}\right)=n H\left(G^{V}\right)-\left(\sum_{i=1}^{n} w_{i}-G^{V}\right) H^{\prime}\left(G^{V}\right) .
$$

It is a simple matter to verify that $G^{V}<G^{*}$.

Now consider a fixed-prize raffle. In this case, individual $i$ chooses wagers $x_{i}$, given the wagers of all other individuals, $x(N \backslash i)$, to maximize expected utility. Thus, individual $i$ 's problem is to choose $x_{i}$ to maximize

$$
U_{i}=\left(w_{i}-x_{i}+\frac{x_{i}}{x(N \backslash i)+x_{i}} R\right) H\left(x(N \backslash i)+x_{i}-R\right)+h_{i}\left(x(N \backslash i)+x_{i}-R\right) .
$$

This leads to the first-order condition

$$
\begin{aligned}
& H^{\prime}\left(x(N \backslash i)+x_{i}-R\right)\left(w_{i}-x_{i}+\frac{x_{i}}{x(N \backslash i)+x_{i}} R\right)+h_{i}^{\prime}\left(x(N \backslash i)+x_{i}\right) \\
& \quad+H\left(x(N \backslash i)+x_{i}\right)\left(-1+\frac{x_{-i}}{\left(x(N \backslash i)+x_{i}\right)^{2}} R\right) \\
& \quad=0 .
\end{aligned}
$$

Let the equilibrium public goods provision be denoted $G^{R}$. Then summing the first-order conditions evaluated at the equilibrium contribution amounts yields

$$
\sum_{i=1}^{n} h_{i}^{\prime}\left(G^{R}\right)=H\left(G^{R}\right)\left(n-(n-1)\left(\frac{R}{R+G^{R}}\right)\right)-H^{\prime}\left(G^{R}\right)\left(\sum_{i=1}^{n} w_{i}-G^{R}\right) .
$$

It is useful to compare expressions (5), (6) and (7). In comparing (6) to (7), notice that the two expressions differ by the term associated with the negative externality of the 
lottery multiplied by $H(G)$. Thus, the public goods provision of the fixed-prize raffle is higher than that under voluntary contributions. Taking the limit of (7) as $R \rightarrow \infty$, we obtain the expression

$$
\sum_{i=1}^{n} h_{i}^{\prime}\left(G^{R}\right)=H\left(G^{R}\right)-H^{\prime}\left(G^{R}\right)\left(\sum_{i=1}^{n} w_{i}-G^{R}\right),
$$

which is of course, identical to (5). To summarize.

Proposition 5. When the public goods allocation decision can be separated from the distribution decision, the fixed-prize raffle increases public goods provision over voluntary contributions. Moreover, as the prize grows large, public goods provision in the raffle converges to first-best from below.

Bergstrom and Cornes note that separability of allocation and distribution is equivalent to there being a representative consumer of public goods. Thus, to the extent that the representative consumer model is appropriate in evaluating the public goods provision of various mechanisms (as is frequently employed in the tax and subsidy literatures), lotteries offer a decentralized means of achieving approximate first-best outcomes.

\section{CONCLUSIONS}

The results of the model offer a number of predictions about how lottery wagering behaviour will change with changes in both the structure of the lottery games as well as the desirability of the public good being financed when public goods allocation decisions can be separated from distribution decisions. Specifically, fixed-prize lotteries are shown to outperform voluntary giving as a means of financing a public good. Indeed, for a given increase in the amount of the prize increases, aggregate lottery wagers increase to a greater extent. Thus, lotteries with larger prizes provide more of the public good. There are limits to this effect: as the size of the prize grows large, the public goods provided by a lottery become close to first-best levels, but do not exceed them. However, the manner in which the lottery is conducted makes a dramatic difference in public goods outcomes. Specifically, pari-mutuel lotteries, where the prize is determined as a percentage of the total bets, are shown to do no better than voluntary contributions in providing a public good.

It is important to notice that these implications differ sharply from models in which lottery play is motivated by risk-seeking, love of gambling, or ignorance. In these models, one would not expect changes in betting behaviour to vary with the social desirability of the public good. It would also be difficult to say how changes in the prize structure of the lottery should affect betting behaviour under these alternative models. Thus, the assumption that individuals pay attention to the link between lottery wagering and the provision of public goods is, in principle, testable along these dimensions.

One possible drawback of employing lotteries in financing public goods is that the linkage between private gain from a lottery and public goods provision may actually reduce a taste for altruism or "warm glow" that individuals obtain through giving behaviour. Depending on the magnitude of this effect, it would certainly narrow (or possibly reverse) the predicted gap between the provision of public goods through voluntary means and that obtained through lotteries.

Further, despite our findings of the desirable welfare properties of lotteries when distributional considerations are absent, lotteries have been shown to be regressive and it may well be the case that these adverse distributional effects override allocational gains from employing the lottery mechanism. Given our focus on the efficiency properties of 
lotteries relative to voluntary contributions, the trade-off between distributional versus allocative welfare gains is beyond the scope of the present study.

That said, our model does suggest that regressive lotteries can be consistent with optimizing behaviour on the part of all individuals. Indeed, if the benefit of the public good is not positively correlated with wealth, then our model predicts that both lotteries and voluntary contributions will be regressive. The possibility that voluntary contributions are also regressive by conventional measures seems relevant in examining whether legal restrictions on operating lotteries run by private charities are advisable. While we are unaware of any formal study examining the regressivity of voluntary contributions, examining voluntary contributions as a percentage of household income yields results consistent

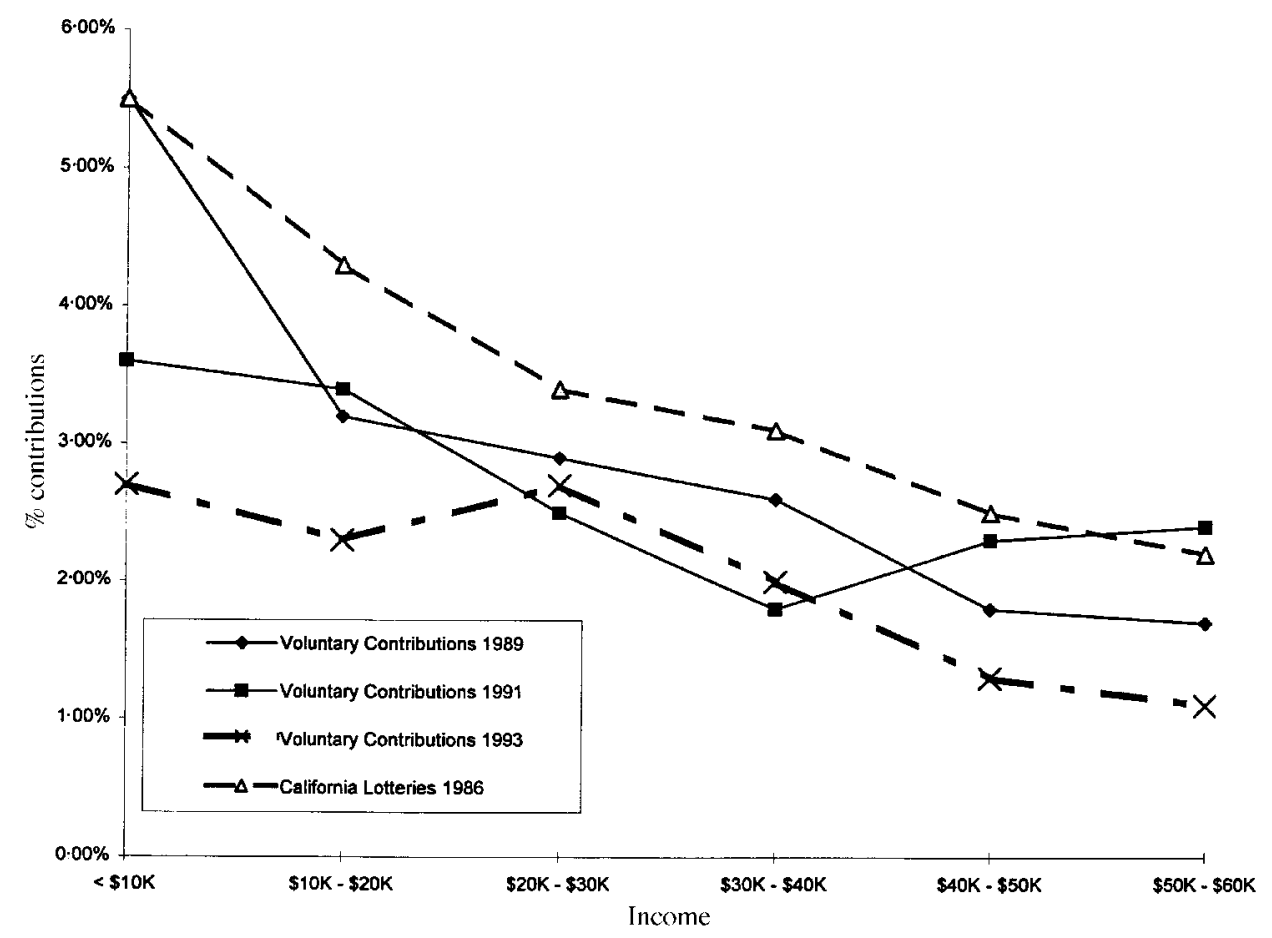

Figure 2

Lotteries vs. voluntary contributions

(Sources: Clotfelter and Cook, Selling Hope; Statistical Abstract of the United States, 1992-1995)

with the theoretical prediction of regressivity in voluntary mechanisms. ${ }^{18}$ (See Figure 2.) Thorough study of the distributional properties of lotteries versus voluntary contributions remains for future research.

\section{APPENDIX}

\section{Proof of Proposition 2}

Before proceeding with the proof, the following preliminary results are helpful.

18. The regressivity observed in Figure 2 arises largely from charitable giving to religious organizations by individuals in lower income groups. 
Define

$$
\psi_{i}(G ; R) \equiv h_{i}^{\prime}(G)-1+\frac{R}{R+G} .
$$

Notice that $\psi_{i}$ is everywhere decreasing in $G$ and increasing in $R$. The expression $\psi_{i}(G ; R)$ represents that marginal benefit (cost) to individual $i$ of increasing her lottery contributions form zero to a small positive amount when the sum of all other contributions provides $G$ of the public good.

Given a prize $R$, let $G_{i}$ solve

$$
\psi_{i}\left(G_{i} ; R\right)=0,
$$

and suppose without loss of generality that $G_{1} \geqq G_{2} \geqq \cdots \geqq G_{n}$.

Lemma 1. An equilibrium exists for the fixed-prize raffle.

Proof. Since the set of $i$ 's actions is compact and convex, and his payoffs are continuous and quasiconcave, the standard existence conditions are satisfied. See Theorem 20.3 Osborne and Rubinstein (1994). II

For circumstances in which an equilibrium provides positive amounts of the public good, the following lemmas hold.

Lemma 2. Any equilibrium generating $G$ of the public good consists of bets $x_{i}>0$ for all $i$ such that $G_{i}>G$ and zero bets from all other bettors.

Proof. Suppose there exists a bettor such that $G_{i}>G$ and $x_{i}=0$, then $\psi_{i}(G ; R)>0$ and it is profitable for $i$ to make a small positive bet. Similarly, suppose there exists a $j$ such that $G_{j} \leqq G$. Then $\psi_{j}(G ; R) \leqq 0$ and it is not profitable to bet any positive amount. I|

Combining the fact that $G_{1} \geqq G_{2} \geqq \cdots \geqq G_{n}$ with Lemma 2 implies that for any level of $G$ only the first $n^{\prime}$ bettors, such that $G_{n^{\prime}} \geqq G>G_{n^{\prime}+1}$, will wager positive amounts in any equilibrium.

Lemma 3. Given an equilibrium where the first $n^{\prime}$ bettors wager positive amounts when all other bettors wager zero, then the wagers of all players and the public goods provision are uniquely determined.

Proof. Summing equations (2) for $i=1, \ldots, n^{\prime}, G_{n^{\prime}}$ solves

$$
\sum_{i=1}^{n^{\prime}} h_{i}^{\prime}(G)-n^{\prime}+\left(n^{\prime}-1\right) \frac{R}{R+G}=0 .
$$

And since the left-hand side of this expression is decreasing, the solution is unique.

The tuple of wagers must also simultaneously satisfy (2) with equality for all $i=1, \ldots, n^{\prime}$. Fixing $G=G_{n^{\prime}}$ then, for $i=1, \ldots, n^{\prime},(2)$ becomes

$$
h_{i}^{\prime}\left(G_{n^{\prime}}\right)-1+\frac{x(N \backslash i)}{R+G_{n^{\prime}}}=0 .
$$

But this is a linear system in $\left(x_{1}, x_{2}, \ldots, x_{n^{\prime}}\right)$, and, since the matrix of coefficients is nonsingular, the solutions are uniquely determined. II

It is useful to show that there are no equilibria in which the raffle fails to be held.

Lemma 4. There is no equilibrium set of wagers $\left(x_{1}, x_{2}, \ldots, x_{n}\right)$ such that $x(N)-R<-\delta$.

Proof. Suppose the contrary is true. Then there is an equilibrium in which the raffle is called off. In this equilibrium, each bettors' utility is simply $w_{i}$.

Now, consider a deviation by bettor $i$. Suppose that $i$ alters his bet such that $x(N)-R=-\delta$. Then the raffle is held and $i$ earns

$$
U_{i}=w_{i}-x_{i}+\frac{x_{i}}{x(N)} R=w_{i}+x_{i}\left(\frac{R}{R-\delta}-1\right)>w_{i},
$$

since $(R /(R-\delta)-1)>0$. Thus, this deviation is profitable for $i$ which contradicts the original supposition. $\quad$ II 
We now proceed to prove Proposition 2.

Proof. From Lemma 1, we know that an equilibrium exists, and from Lemma 4, we know that, in equilibrium, the raffle is held.

Suppose a set $N^{\prime} \subseteq N$ players bidding positive amounts constitutes an equilibrium. Then, for all $i \in N^{\prime}$

$$
h_{i}^{\prime}\left(G_{N^{\prime}}\right)-1+\frac{R x(N \backslash i)}{\left(R+G_{N^{\prime}}\right)^{2}}=0,
$$

for all $j \in N \backslash N^{\prime}$

$$
h_{j}^{\prime}\left(G_{N^{\prime}}\right)-1+\frac{R}{R+G_{N^{\prime}}} \leqq 0 .
$$

By Lemma 3, there is a unique equilibrium involving $N^{\prime}$ positive bettors.

Combining the fact that $G_{1} \geqq G_{2} \geqq \cdots \geqq G_{n}$ with Lemma 2, attention may be restricted to subsets and supersets of $N^{\prime}$. This follows from the fact that any equilibrium provision of the public good must either result in $N^{\prime}$ and some additional bettors wagering positive amounts, or marginal players in $N^{\prime}$ dropping out according to the size of $G_{i}$ relative to the equilibrium $G$.

Case 1. Suppose that there exists a set $N^{\prime \prime} \subseteq N^{\prime}$ that also constitutes an equilibrium. Then $N^{\prime \prime}$ satisfies $i \in N^{\prime \prime} \subseteq N^{\prime}$

$$
h_{i}^{\prime}\left(G_{N^{\prime \prime}}\right)-1+\frac{R x(N \backslash i)}{\left(R+G_{N^{\prime \prime}}\right)^{2}}=0 .
$$

For $k \in N^{\prime} \backslash N^{\prime \prime}$

$$
h_{k}^{\prime}\left(G_{N^{\prime \prime}}\right)-1+\frac{R}{R+G_{N^{\prime \prime}}} \leqq 0,
$$

and for $j \in N \backslash N^{\prime}$

$$
h_{j}^{\prime}\left(G_{N^{\prime \prime}}\right)-1+\frac{R}{R+G_{N^{\prime \prime}}} \leqq 0 .
$$

Notice that for (8) to hold, then $G_{N^{\prime \prime}}>G_{N^{\prime}}$.

Recall that $G_{N^{\prime \prime}}$ solves

$$
\sum_{i \in N^{\prime \prime}} h_{i}^{\prime}(G)-N^{\prime \prime}+\left(N^{\prime \prime}-1\right) \frac{R}{R+G}=0
$$

evaluating this expression at $G_{N^{\prime}}$ yields

$$
\sum_{i \in N^{\prime \prime}} h_{i}^{\prime}\left(G_{N^{\prime}}\right)-N^{\prime \prime}+\left(N^{\prime \prime}-1\right) \frac{R}{R+G_{N^{\prime}}}<0,
$$

since, summing (2) over the set $N^{\prime \prime}$ of players yields

$$
\begin{array}{r}
\sum_{i \in N^{\prime \prime}} h_{i}^{\prime}\left(G_{N^{\prime}}\right)-N^{\prime \prime}+\sum_{i \in N^{\prime \prime}} x\left(N^{\prime} \backslash i\right) \frac{R}{x\left(N^{\prime}\right)^{2}}=0, \\
\sum_{i \in N^{\prime \prime}} h_{i}^{\prime}\left(G_{N^{\prime}}\right)-N^{\prime \prime}+\frac{1}{x\left(N^{\prime}\right)}\left(\left(N^{\prime \prime}-1\right) x\left(N^{\prime}\right)+x\left(N^{\prime} \backslash N^{\prime \prime}\right)\right) \frac{R}{R+G_{N^{\prime}}}=0, \\
\sum_{i \in N^{\prime \prime}} h_{i}^{\prime}\left(G_{N^{\prime}}\right)-N^{\prime \prime}+\left[\left(N^{\prime \prime}-1\right)+\frac{x\left(N^{\prime} \backslash N^{\prime \prime}\right)}{x\left(N^{\prime}\right)}\right] \frac{R}{R+G_{N^{\prime}}}=0,
\end{array}
$$

but the inequality in (9) implies $G_{N^{\prime}}$ which is a contradiction $N^{\prime}$ of players constituting an equilibrium. Then for $i \in N^{\prime}$

$$
h_{i}^{\prime}\left(G_{N^{\prime \prime}}\right)-1+\frac{R x(N \backslash i)}{\left(R+G_{N^{\prime \prime}}\right)^{2}}=0 .
$$

For $k \in N^{\prime \prime} \backslash N^{\prime}$

$$
h_{k}^{\prime}\left(G_{N^{\prime \prime}}\right)-1+\frac{R x(N \backslash i)}{\left(R+G_{N^{\prime \prime}}\right)^{2}}=0,
$$


and for $j \in N \backslash N^{\prime \prime}$

$$
h_{j}^{\prime}\left(G_{N^{\prime \prime}}\right)-1+\frac{R}{R+G_{N^{\prime \prime}}} \leqq 0 .
$$

Case 2. Suppose that there exists a set $N^{\prime \prime} \supseteq$

To induce additional bidders to join the bidding requires $G_{N^{\prime \prime}}<G_{N^{\prime}}$.

Since

$$
\sum_{i \in N^{\prime}} h_{i}^{\prime}\left(G_{N^{\prime}}\right)-N^{\prime}+\left(N^{\prime}-1\right) \frac{R}{R+G_{N^{\prime}}}=0,
$$

then if $G_{N^{\prime \prime}}<G_{N^{\prime}}$

$$
\sum_{i \in N^{\prime}} h_{i}^{\prime}\left(G_{N^{\prime \prime}}\right)-N^{\prime}+\left(N^{\prime}-1\right) \frac{R}{R+G_{N^{\prime \prime}}}>0 .
$$

Summing the FOCs over the $N^{\prime}$ players

$$
\sum_{i \in N^{\prime}} h_{i}^{\prime}\left(G_{N^{\prime \prime}}\right)-N^{\prime}+\frac{R}{\left(R+G_{N^{\prime \prime}}\right)^{2}}\left[\sum_{N^{\prime}} x(N \backslash i)\right]=0 .
$$

We can rewrite the left-hand side of (11) as

$$
\sum_{i \in N^{\prime}} h_{i}^{\prime}\left(G_{N^{\prime \prime}}\right)-N^{\prime}+\left[\left(N^{\prime}-1\right)+x\left(N^{\prime \prime} \backslash N^{\prime}\right)\right] \frac{R}{R+G_{N^{\prime \prime}}}>\sum_{i \in N^{\prime}} h_{i}^{\prime}\left(G_{N^{\prime \prime}}\right)-N^{\prime}+\left(N^{\prime}-1\right) \frac{R}{R+G_{N^{\prime \prime}}}>0,
$$

by equation (10). But this is a contradiction.

Since Cases 1 and 2 are exhaustive, the proof is complete. II

\section{Proof of Theorem 1}

Before proceeding, the following lemma proves useful.

Lemma 5. In a fixed-prize raffle, if the number of positive bettors remains fixed, then the provision of the public good is increasing in the amounts of the prize.

Proof. By Proposition 2, there is a unique set of $N^{\prime}$ bettors with equilibrium wagers $\left(\bar{x}_{1}, \bar{x}_{2}, \ldots, \bar{x}_{n}\right)$ such that summing (2) over the first $n^{\prime}$ bettors yields

$$
\sum_{i=1}^{n^{\prime}} h_{i}^{\prime}(\bar{x}(N)-R)-n^{\prime}+\left(n^{\prime}-1\right) \frac{R}{\bar{x}(N)}=0 .
$$

Totally differentiating and rearranging

$$
\frac{\partial \bar{x}(N)}{\partial R}=\frac{-\sum_{i=1}^{n^{\prime}} h_{i}^{\prime \prime}(\bar{x}(N)-R)+\left(n^{\prime}-1\right)(1 / \bar{x}(N))}{-\sum_{i=1}^{n^{\prime}} h_{i}^{\prime \prime}(\bar{x}(N)-R)+\left(n^{\prime}-1\right)(1 / \bar{x}(N))(R / \bar{x}(N))} \geqq 1,
$$

where the inequality follows from the fact that $R / \bar{x}(N)<1$; hence the denominator is smaller than the numerator.

Recall that $\partial \bar{G} / \partial R=(\partial(\bar{x}(N)-R) / \partial R)=(\partial \bar{x}(N) / \partial R)-1$. Hence

$$
\frac{\partial \bar{G}}{\partial R} \geqq 0,
$$

with strict inequality provided $n^{\prime}>1$. Thus, the claim is proven. $\|$

We now proceed to prove Theorem 1.

Proof. Recall that under voluntary contributions $x^{V}(N)$ solves

$$
\sum_{i=1}^{n^{V}} h_{i}^{\prime}\left(x^{V}(N)-R\right)-n^{V}+\left(n^{V}-1\right) \frac{R}{R+G^{V}}=0,
$$

when $R=0$ and $i=1, \ldots, n^{V}$ bettors contribute positive amounts. 
Case 1. If the set of positive bettors is unchanged by the introduction of a raffle, then, by Lemma 5 , the provision of the public good is higher.

Case 2. Suppose that the set of positive bettors changes. Suppose bettor $i$ drops out with the introduction of the raffle, then

$$
\psi_{i}\left(G^{V} ; 0\right)>0
$$

and

$$
\psi_{i}(\bar{G} ; R)<0,
$$

and since $\psi_{i}$ is decreasing in $G$ and increasing in $R$, then $\bar{G}>G^{V}$ is necessary for this to happen.

Suppose that the introduction of the raffle induces bettors $n^{V}+1, \ldots, n^{V}+k$ to bet positive amounts, then $G$ must also increase.

To see this note that $G^{V}$ solves

$$
\psi_{i}\left(G^{V} ; 0\right)=0
$$

and with the fixed-prize raffle $\bar{G}$ solves

$$
\sum_{i=1}^{n^{V}+k} \psi_{i}(\bar{G} ; R)-\frac{R}{R+\bar{G}}=0 .
$$

Differencing yields

$$
\sum_{i=1}^{n^{V}}\left(h_{i}^{\prime}(\bar{G})-h_{i}^{\prime}\left(G^{V}\right)\right)+\sum_{i=n^{V}+1}^{n^{V}+k} \psi_{i}(\bar{G} ; R)+\left(n^{V}-1\right) \frac{R}{R+\bar{G}}=0,
$$

but if $\bar{G} \leqq G^{V}$ then all the terms in this expression are positive, which is a contradiction. Thus, $\bar{G}>G^{V}$.

Since Cases 1 and 2 are exhaustive, the proof is complete. II

\section{Proof of Theorem 2}

The following lemma is helpful in the proof.

Lemma 6. In a fixed-prize raffle, if a prize $R \geqq \bar{R}$ is offered, then all bettors wager positive amounts.

Proof. Recall that it is profitable for $i$ to wager a positive amount provided

$$
\psi_{i}(G ; R)>0 \text {. }
$$

Let $\bar{R}$ solve

$$
\psi_{n}\left(G^{*} ; \bar{R}\right)=0
$$

An implication of equation (3) is that all equilibrium provisions of the public good are less than $G^{*}$. Hence, for any equilibrium $\bar{G}$,

$$
\psi_{n}(\bar{G} ; \bar{R})>0
$$

and since $G_{1} \geqq G_{2} \geqq \cdots \geqq G_{N}$, then for all $i$

$$
\psi_{i}(\bar{G} ; \bar{R}) \geqq \psi_{n}(\bar{G} ; \bar{R}),
$$

and all bettors will wager positive amounts. Since, $\psi_{i}$ is increasing in $R$, then for all $R \geqq \bar{R}$, all bettors will likewise wager positive amounts. $\|$

We proceed to prove Theorem 2 .

Proof. Without loss of generality, let $R^{*}>\bar{R}$, then, by Lemma 6, attention can be restricted to strictly interior equilibria.

The $G$ generated by $R^{*}$ solves

$$
\sum_{i=1}^{n} h_{i}^{\prime}(G)-n+(n-1) \frac{R}{R+G}=0 .
$$


As $R \rightarrow \infty, G \rightarrow G^{*}$; moreover, by Lemma 5, $G$ is increasing in $R$. Hence, for some $\bar{G} \in\left[G^{*}-\varepsilon, G^{*}\right)$, there exists $R^{*}$ such that

$$
\sum_{i=1}^{n} h_{i}^{\prime}(\bar{G}-\varepsilon)-n+(n-1) \frac{R^{*}}{R^{*}+\bar{G}}=0,
$$

and provided $\sum_{i=1}^{n} w_{i}^{*}$ is sufficiently large, $R^{*}$ is a feasible prize. $\|$

\section{Proof of Theorem 3}

First, suppose the raffle funds the public good.

If $\left(\bar{x}_{1}, \bar{x}_{2}, \ldots, \bar{x}_{n}\right)$ are the equilibrium wages then the equilibrium equation of bettor $i$ for the raffle is

$$
h_{i}^{\prime}(x(N)-R)=1-\left(\frac{x(N \backslash i)}{(x(N))^{2}}\right) R,
$$

provided that $\bar{x}_{i}>0$. Suppose $n^{\prime}<n$ players wager positive amounts, then summing over all $n^{\prime}$ players yields

$$
\sum_{i=1}^{n^{\prime}}\left(h_{i}^{\prime}(x(N)-R)\right)=n^{\prime}-\left(n^{\prime}-1\right) \frac{R}{x(N)} a .
$$

If a raffle funds the public good, i.e. then (12) implies

$$
\sum_{i=1}^{n^{\prime}}\left(h_{i}^{\prime}(0)\right) \geqq 1,
$$

and hence

$$
\sum_{i=1}^{n}\left(h_{i}^{\prime}(0)\right) \geqq 1 .
$$

Thus, from (1), $G^{*}>0$, and the public good is socially desirable.

Conversely, suppose the good is socially desirable and is not funded by the raffle. Recall that social desirability requires

$$
\sum_{i=1}^{n} h_{i}^{\prime}(0) \geqq 1,
$$

and, from (12), a necessary condition for a raffle not to fund the good is

$$
\sum_{i=1}^{n} h_{i}^{\prime}(0)<1 .
$$

But this is clearly a contradiction. $\|$

Acknowledgements. The author wishes to thank Mike Baye, Keith Crocker, Kala Krishna, Vijay Krishna, and the participants of the workshops at Harvard, Penn State, Princeton, and Toulouse for helpful comments. The paper has also benefitted greatly from the comments of several anonymous referees and the editor. Special thanks to Heather Morgan for her patience and insight.

\section{REFERENCES}

ADMATI, A. and PERRY, M. (1991), “Joint Projects without Commitment”, Review of Economic Studies, 58, 259-276.

ANDREONI, J. (1998), "Privately Provided Public Goods in a Large Economy: the Limits of Altruism", Journal of Public Economics, 35, 57-73.

ANDREONI, J. and BERGSTROM, T. (1996), "Do Government Subsidies Increase the Supply of Public Goods", Public Choice, 88, 295-308.

BAGNOLI, M. and LIPMAN, B. (1989), "Provision of Public Goods: Fully Implementing the Core through Private Contributions", Review of Economic Studies, 56, 583-602.

BERGSTROM, T., BLUME, L. and VARIAN, H. (1986), "On the Private Provision of Public Goods", Journal of Public Economics, 29, 25-49.

BERGSTROM, T. and CORNES, R. (1983), "Independence of Allocative Efficiency from Distribution in the Theory of Public Goods", Econometrica, 51, 1753-1765.

BERNHEIM, B. D. (1986), "On the Voluntary and Involuntary Provision of Public Goods", American Economic Review, 76, 789-793.

BORG, M. and MASON, P. (1988), "The Budgetary Incidence of a Lottery to Support Education", National Tax Journal, 61, 75-85.

BORG, M., MASON, P. and SHAPIRO, S. (1991) The Economic Consequences of State Lotteries (New York: Praeger Publishers).

BUCHANAN, J. (1963), “The Economics of Earmarked Taxes”, Journal of Political Economy, 71, 457-469. 
CHEN, Y. and TANG, F.-F. (1998), "Learning and Incentive-Compatible Mechanisms for Public Goods Provision", Journal of Political Economy, 106, 633-662.

ClOTFELTER, C. and COOK, P. (1987), "Implicit Taxation in Lottery Finance", National Tax Journal, 40, $533-546$.

ClOTFElTER, C. and COOK, P. (1989) Selling Hope, State Lotteries in America (Cambridge: Harvard University Press).

CORNES, R. and SANDLER, T. (1984), "Easy Riders, Joint Production, and Public Goods", Economic Journal, 94, 580-598.

CORNES, R. and SANDLER, T. (1994), "The Comparative Static Properties of the Impure Public Good Model", Journal of Public Economics, 54, 403-421.

DeBOER, L. (1990), “Lotto Sales Stagnation: Product Maturity or Small Jackpots”? Growth and Change, 21, 73-77.

DOUGLAS, A. (1995) British Charitable Gambling 1956-1994 (London: Athlone Press).

GOETZ, C. (1968), "Earmarked Taxes and Majority Rule”, American Economic Review, 58, $128-136$.

GROVES, T. and LEDYARD, J. (1977), "Optimal Allocation of Public Goods: A Solution to the Free Rider Problem”, Econometrica, 45, 783-809.

GULLY, D. and SCOTT, F. (1993), “The Demand for Wagering on State Operated Lotto Games”, National Tax Journal, 46, 13-22.

HARSTAD, R. and MARESSE, M. (1982), "Behavioral Explanations of Efficient Public Good Allocations", Journal of Public Economics, 19, 367-383.

HINES, J. and THALER, R. (1995), "The Flypaper Effect", Journal of Economic Perspectives, 9, $217-226$.

ISAAC, M. and WALKER, J. (1988), "Communication and Free-Riding Behavior: The Voluntary Contributions Mechanism”, Economic Inquiry, 28, 585-608.

ISAAC, M., SCHMIDTZ, D. and WALKER, J. (1989), "The Assurance Problem in a Laboratory Market", Public Choice, 62, 217-236.

KARCHER, A. (1989) Lotteries (New Brunswick: Transaction Publishers).

LA FLEUR, T. and LA FLEUR B., "Lottery FAQ", in La Fleur's Lottery World, (http://www.lafleurs.com).

LEDYARD, J. (1995), "Public Goods: A Survey of Experimental Research", in Kagel, J. and Roth, A. (eds.), The Handbook of Experimental Economics (Princeton: Princeton University Press).

MOORE, J. (1992), "Implementation, Contracts, and Renegotiation in Environments with Complete Information", in Laffont, J.-J. (ed.), Advances in Economic Theory: Sixth World Congress, Vol. 1 (New York: Cambridge University Press).

MORGAN, J. and SEFTON, M. (1996), "Funding Public Goods through Lotteries: An Experiment", Review of Economic Studies, 67, 785-810.

OSBORNE, M. and RUBINSTEIN, A. (1994) A Course in Game Theory (Cambridge: MIT Press).

ROBERTS, R. (1987), "Financing Public Goods", Journal of Political Economy, 95, 420-437.

U.S. DEPARTMENT OF COMMERCE, Statistical Abstract of the United States, Economics and Statistics, 1992-1995.

WALKER, M. (1981), “A Simple Incentive Compatible Scheme for Attaining Lindahl Allocations”, Econometrica, 49, 65-71.

WARR, P. (1982), "Pareto Optimal Redistribution and Private Charity", Journal of Public Economics, 19, 131-138.

WEESIE, J. (1990), "Participation in Voluntary Organizations and Group Size", Rationality and Society, 2 , $35-66$. 